\title{
GERMINAÇÃO DE SEMENTES DE JENIPAPO: TEMPERATURA, SUBSTRATO E MORFOLOGIA DO DESENVOLVIMENTO PÓS-SEMINAL ${ }^{1}$
}

\author{
ANTÔNIO CARLOS SILVA DEANDRADE ${ }^{2}$, ALEXANDRE FADIGAS DE SOUZA ${ }^{3}$, FLAVIO NUNES RAMOS ${ }^{3}$, \\ TÂNIA SAMPAIO PEREIRA ${ }^{4}$ e ANA PAULA MARTINS CRUZ ${ }^{3}$
}

\begin{abstract}
RESUMO - O presente trabalho teve como objetivos definir o tipo de substrato e a temperatura mais adequados à germinação de sementes de jenipapo (Genipa americana L.), conhecer a morfologia das sementes e seu desenvolvimento pós-seminal, caracterizando as plântulas normais, o tipo de germinação e os padrões de anormalidade. Para tanto, realizou-se um experimento colocando-se as sementes sobre os seguintes substratos: papel, vermiculita e solo, nas temperaturas constantes de $20^{\circ} \mathrm{C}, 25^{\circ} \mathrm{C}$, $30^{\circ} \mathrm{C}$, e $35^{\circ} \mathrm{C}$ e alternada de $20^{\circ} \mathrm{C}-30^{\circ} \mathrm{C}$. O delineamento estatístico empregado foi o inteiramente casualizado $(5 \times 3)$, com quatro repetições de 50 sementes. Foram analisados os parâmetros germinação normal (\%) e velocidade de germinação. Os melhores resultados foram obtidos nas temperaturas constantes de $25^{\circ} \mathrm{C}, 30^{\circ} \mathrm{C}$ e $35^{\circ} \mathrm{C}$, e nos substratos vermiculita e solo.
\end{abstract}

Termos para indexação: plântula, Genipa americana.

SEED GERMINATION OF GENIPA AMERICANA L. - RUBIACEAE: TEMPERATURE, SUBSTRATE AND POST-SEMINAL DEVELOPMENT

\begin{abstract}
This study aimed to define the best substrate and temperature for germination of genipap (Genipa americana L. - Rubiaceae) seeds, and to describe the morphology of its seeds, postseminal development, normal and abnormal seedlings. The experiment was designed according to a $5 \times 3$ factorial with constant temperatures of $20^{\circ} \mathrm{C}, 25^{\circ} \mathrm{C}, 30^{\circ} \mathrm{C}$ and $35^{\circ} \mathrm{C}$ and alternated $20^{\circ} \mathrm{C}-30^{\circ} \mathrm{C}$ in filter paper, vermiculite and soil substrates. The following parameters were analyzed: normal percentage germination and speed of germination. The $25^{\circ} \mathrm{C}, 30^{\circ} \mathrm{C}$ and $35^{\circ} \mathrm{C}$ temperatures and vermiculite and soil substrates were the best conditions for seed germination.
\end{abstract}

Index terms: seedling, genipap.

\section{INTRODUÇÃO}

Genipa americana L., conhecida popularmente como jenipapo ou jenipá, é uma Rubiacea de porte arbóreo, com características de planta heliófita, semidecídua, seletiva higrófita, de ocorrência em áreas com florestas abertas e de vegetação secundá-

\footnotetext{
${ }^{1}$ Aceito para publicação em 26 de março de 1999.

${ }^{2}$ Eng. Agrôn., M.Sc., Laboratório de Sementes, Instituto de Pesquisas Jardim Botânico do Rio de Janeiro (JBRJ), Rua Pacheco Leão 915, CEP 22460-030 Rio de Janeiro, RJ. E-mail: acsandrade@hotmail.com

${ }^{3}$ Biól., JBRJ.

${ }^{4}$ Biól., M.Sc., JBRJ.
}

ria de várzeas situadas em locais temporário ou permanentemente inundados. Com ampla distribuição pelas regiões tropicais úmidas e subtropicais da América Latina desde o México até a Argentina, a espécie parece desenvolver-se melhor em áreas com pluviosidade entre 1.200 e $4.000 \mathrm{~mm}$ e com temperaturas médias anuais entre $18^{\circ} \mathrm{C}$ e $28^{\circ} \mathrm{C}$. No Brasil, sua ocorrência vai do Amapá aos estados do sul (FAO, 1986; Lorenzi, 1992).

Historicamente, o primeiro produto extraído do jenipapo seria uma tintura azul-escura à base de tanino, que, para os ameríndios pré-colombianos, apresentava propriedades mágicas e medicinais. Sua madeira é amplamente usada nas construções civil e naval, e marcenaria. Seu fruto, quando maduro, fornece polpa que pode ser consumida in natura ou na forma de sucos (FAO, 1986). Por suportar lon- 
gos períodos sob condições de alagamento, o jenipapo tem sido utilizado como espécie promissora em modelos de recuperação de áreas degradadas em ambientes de mata ciliar no Estado de São Paulo (Barbosa et al., 1989).

Apesar do aumento considerável de dados de análise de sementes de espécies nativas, muitas ainda carecem de informações básicas referentes às condições ideais de germinação. Tal afirmação pode ser verificada nas Regras para Análise de Sementes (Brasil, 1992), onde são encontradas poucas recomendações ou prescrições para análise de espécies florestais, embora muitas sejam intensamente cultivadas. Este parece ser o caso das sementes de jenipapo, em que tanto a temperatura como o substrato ótimo para a germinação são desconhecidos; tal fato prejudica a avaliação da qualidade das sementes, principalmente quando é necessário comparar resultados obtidos em diferentes laboratórios.

A temperatura apresenta grande influência tanto na porcentagem como na velocidade de germinação, influenciando a absorção de água pela semente e as reações bioquímicas que regulam o metabolismo envolvido nesse processo (Bewley \& Black, 1994). Segundo Mayer \& Poljakoff-Mayber (1989), pode ser considerada como ótima a temperatura na qual a mais alta porcentagem de germinação seja obtida, dentro do menor espaço de tempo. Seriam consideradas ainda a mínima e a máxima, respectivamente, como a mais baixa e a mais alta temperatura em que a germinação ocorre.

As espécies apresentam grande variação quanto à temperatura ideal de germinação de suas sementes, cuja faixa, de forma geral, está situada entre as temperaturas encontradas em sua região de origem, na época propícia à emergência natural. Desta forma, existem espécies cujo processo germinativo é favorecido por temperaturas constantes (Carneiro et al., 1987; Andrade \& Pereira, 1994), por alternância de temperaturas (Vázquez-Yanes \& Orozco-Segovia, 1982) e por insensibilidade ao regime de temperaturas utilizado (Albrecht et al., 1986).

O substrato também apresenta influência nos testes de germinação, já que fatores como aeração, estrutura, capacidade de retenção de água, grau de infestação de patógenos, entre outros, podem variar de acordo com o tipo de material utilizado
(Popinigis, 1985). O substrato deve manter proporção adequada entre a disponibilidade de água e aeração, não devendo ser umedecido em excesso para evitar que a película de água envolva completamente a semente, restringindo a entrada e absorção de oxigênio (Villagomez et al., 1979). Sendo assim, a escolha do tipo de substrato deve ser feita em função das exigências da semente em relação ao seu tamanho e formato (Brasil, 1992).

O conhecimento da morfologia da semente e da plântula nos estádios iniciais de desenvolvimento contribui tanto para a Sistemática quanto para a Ecologia, no estudo das espécies tropicais (Parra, 1984; Oliveira, 1993; Garwood, 1995). Negligenciado até recentemente, devido, em parte, à falta de tradição no uso dessas características, e em parte, à falta de informações acerca da biologia reprodutiva de alguns taxa, o estudo da morfologia de sementes e plântulas de espécies tropicais tem, entretanto, recebido progressiva atenção dos pesquisadores (Miquel, 1987; Oliveira \& Beltrati, 1992; Andrade \& Pereira, 1994; Garwood, 1995).

Objetivou-se, no presente trabalho, estudar os efeitos de diferentes temperaturas e substratos na germinação de sementes de jenipapo, e conhecer a morfologia da semente e o desenvolvimento pós-seminal, que caracterizam a plântula normal e os padrões de anormalidade.

\section{MATERIAL E MÉTODOS}

Sementes de jenipapo (Genipa americana L.) foram obtidas a partir de frutos maduros, coletados em árvores existentes no Arboreto do Jardim Botânico do Rio de Janeiro (JBRJ). Após o beneficiamento, as sementes foram armazenadas sob temperatura de $15^{\circ} \mathrm{C}$, durante cinco dias, com grau de umidade e germinação iniciais de $51,3 \%$ e $88 \%$, respectivamente, no Laboratório de Sementes do JBRJ, até o início da montagem dos experimentos.

As sementes foram submetidas a germinação, sob temperaturas constantes de $20^{\circ} \mathrm{C}, 25^{\circ} \mathrm{C}, 30^{\circ} \mathrm{C}$ e $35^{\circ} \mathrm{C}$, e alternada, de $20^{\circ} \mathrm{C}-30^{\circ} \mathrm{C}$, com fotoperíodo de oito horas, utilizando lâmpadas fluorescentes do tipo luz do dia $(4 \times 20 \mathrm{~W})$, com densidade do fluxo radiante na altura das sementes de $20 \mathrm{~mol} / \mathrm{m}^{2} / \mathrm{s}$. As sementes foram colocadas sobre os seguintes substratos: vermiculita, solo e papel de filtro, preparados de acordo com as Regras para Análise de Sementes (Brasil, 1992). 
Os tratamentos foram esquematizados em delineamento inteiramente casualizado $(5 \times 3)$, com quatro repetições de 50 sementes, dispostas em recipientes de plástico do tipo gerbox, sendo avaliada a germinação (\%), considerando-se somente as plântulas que apresentavam as estruturas essenciais em perfeito estado de desenvolvimento, e o índice de velocidade de germinação - IVG - (Maguire, 1962), calculado pela soma de plântulas normais, multiplicado pelo inverso do número de dias ocorridos do plantio à contagem. A germinação foi avaliada a cada dois dias, com a contagem final realizada após 70 dias do início dos experimentos.

Os resultados em porcentagem foram transformados em arco seno $(\% / 100)^{1 / 2}$ para normalização de sua distribuição. Foi utilizado o teste de Tukey a $5 \%$ de probabilidade, para comparação entre as médias, e houve significância pelo teste F (Steel \& Torrie, 1980).

Após prévia descrição biométrica (média \pm desvio-padrão) e morfológica de 100 sementes, foi realizada, em dias alternados, a descrição morfológica durante o desenvolvimento pós-seminal. As ilustrações foram feitas com auxílio de estereomicroscópio óptico (5x), equipado com câmara clara. Os critérios estabelecidos para caracterizar a plântula normal e os tipos de anormalidades basearam-se nas Regras para Análise de Sementes (Brasil, 1992), utilizando-se a terminologia de Stearn (1983).

\section{RESULTADOS E DISCUSSÃO}

\section{Morfologia da semente, do desenvolvimento pós-se- minal, e da plântula}

O estudo morfológico permitiu descrever a semente de Genipa americana $[\mathrm{n}=100 ; 8,54( \pm 0,11)$ x 6,45 $( \pm 0,08)$ x $2,1( \pm 0,03) \mathrm{mm}$; peso médio $=0,0963 \mathrm{~g}( \pm 0,0012 \mathrm{~g})]$ (Fig. 1a-1c) como lenticular-comprimida, de obovada a irregularmente arredondada em seção longitudinal, e elíptica em seção transversal. Faces planas ou levemente convexas, com bordos arredondados e levemente acuminado na base. Tegumento delgado $(<1 \mathrm{~mm})$, de superfície parda (semente madura), opaca e levemente rugosa; cicatrizes seminais não discerníveis. Enquanto úmida, a semente permanece envolta por camada mucilaginosa remanescente do endocarpo que, depois de seca, permanece aderida à superfície como uma película pardo-esbranquiçada. Endosperma córneo e embrião espatulado; em seção transversal, o eixo hipocótilo-radícula é circular, e os cotilédones, justapostos, são ovados em vista frontal.

Do ponto de vista morfológico, a germinação (Fig. 1d-1g) iniciou-se entre 8 e 13 dias, pelo rompimento dos tegumentos e protrusão da radícula, com densa zona pilífera. O hipocótilo se projeta juntamente com a radícula. Os cotilédones emergem e se expandem entre o $17^{\circ}$ e o $34^{\circ}$ dia, após um período de crescimento simultâneo do hipocótilo e da raiz principal, quando surgem raízes secundárias. A plântula normal (Fig. 1g) é faneroepígea (Duke \& Polhill, 1981), apresentando raiz principal axial e robusta, com raízes secundárias numerosas e bem desenvolvidas, de coloração pardo-esbranquiçada. O hipocótilo é verde, cilíndrico, longo $(3,68 \pm 0,11 \mathrm{~cm} ; \mathrm{n}=30)$ e glabro; a plúmula é reduzida e pouco distinguível, com cotilédones oblongos e reflexos, curto-peciolados, glabros, membranosos, verdes discolores, com nervura central bem marcada. Os eófilos emergem entre o 770 e o 960 dia, sendo lanceolados, de ápices e bases acuminados e margens inteiras, verdes discolores, opostos, curto-peciolados e cruzados em relação aos cotilédones, dos quais são separados por um curto epicótilo. A forma geral dos eófilos se assemelha à das folhas adultas.

Plântulas anormais de Genipa americana, com má formação congênita, ocorreram em maior freqüência do que as portadoras de anormalidades provocadas pelo substrato ou acondicionamento inadequado, tais como ressecamento da raiz por exposição ao ar, verificado no substrato papel de filtro (Fig. 1j). As plântulas anormais apresentaram radícula necrosada (Fig. 1h), raiz principal truncada e necrosada na extremidade (Fig. 1i), cotilédones, ainda encerrados nos tegumentos, com hipocótilo desenvolvido e sistema radicular ressecado e necrosado (Fig. 1j), sistema radicular normal, hipocótilo desenvolvido, e cotilédones deformados e pouco desenvolvidos, ou com manchas amareladas e pontos enegrecidos (Fig. 1k).

A classificação morfológica de Duke (1969), referente às plântulas de Genipa americana, é de germinação fanerocotiledonar em que os cotilédones, expandidos, são elevados pelo hipocótilo acima do substrato. De acordo com Vogel (1980), as plântulas com características semelhantes, de cotilédones persistentes, fotossintetizantes expandidos e elevados 
pelo hipocótilo acima do nível do solo, estariam classificadas no tipo Macaranga. Mais recentemente, Miquel (1987) utilizou três critérios observáveis durante a coleta das plântulas no campo (cotilédones livres ou encerrados nos tegumentos da semente, desenvolvimento do hipocótilo e natureza dos cotilédones livres, se carnosos ou foliáceos), para classificá-las em cinco tipos. Segundo essa classificação, a plântula de Genipa americana seria epígeofoliácea. Porém, a classificação mais adequada para a espécie é faneroepígea (Duke \& Polhill, 1981), por todas as características citadas pelos demais autores e, ainda, pelo fato de permanecerem dependen-

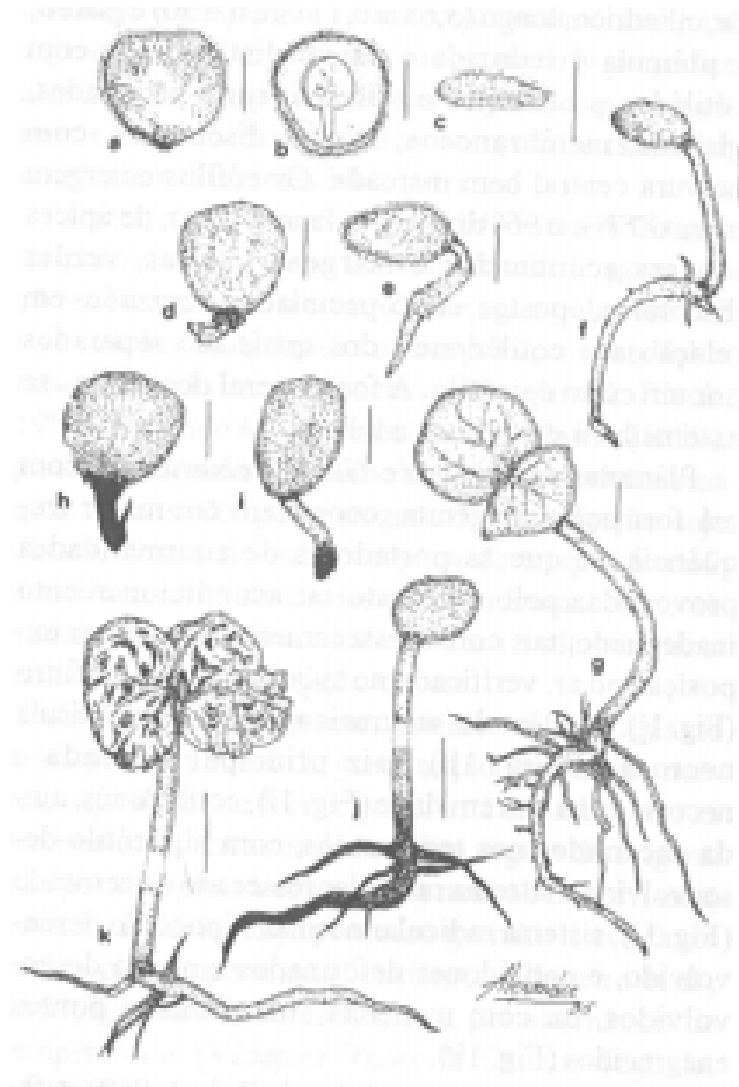

FIG. 1. Morfologia da semente, do desenvolvimento pós-seminal e da plântula de G. americana. a-c: aspectos externos e internos da semente, em contornos longitudinal e transversal; d-g: fases da germinação; g - plântula normal. h-k: padrões de anormalidade na germinação. Escala: 5 mm. tes dos cotilédones até o estabelecimento das primeiras folhas no sítio definitivo para completar seu desenvolvimento.

\section{Influência do substrato e da temperatura}

A avaliação do processo germinativo em dias alternados permitiu a confecção das curvas de germinação cumulativas (Fig. 2). Verificou-se que a máxima germinação foi obtida aos 70 dias; aos 28 dias de ensaio, cerca de $20 \%$ de plântulas haviam se formado por completo, principalmente sobre o substrato solo, na temperatura de $30^{\circ} \mathrm{C}$. Aos 42 dias, $78 \%$ das plântulas se formaram; a partir dos 70 dias, as curvas de germinação começaram a se estabilizar, e não foi mais observada a germinação.
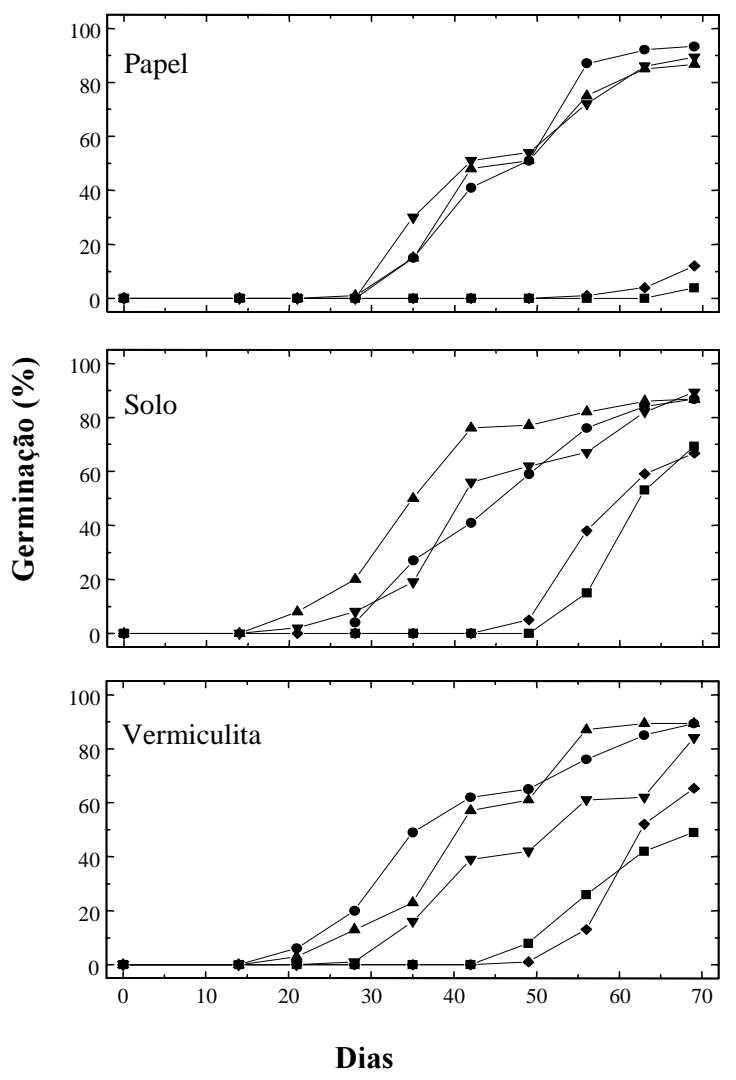

FIG. 2. Germinação cumulativa de sementes de G. americana em diferentes substratos, nas temperaturas de $20^{\circ} \mathrm{C}(\bullet), 25^{\circ} \mathrm{C}(\bullet), 30^{\circ} \mathrm{C}(\Delta)$, $35^{\circ} \mathrm{C}(\nabla)$ e $20^{\circ} \mathrm{C}-30^{\circ} \mathrm{C}(\bullet)$. 
Os resultados de germinação (\%) são apresentados na Tabela 1. A partir da interação significativa do substrato $\mathrm{x}$ temperatura, observou-se que no substrato vermiculita, a temperatura de $20^{\circ} \mathrm{C}$ foi estatisticamente inferior às demais temperaturas, com exceção da temperatura de $20^{\circ} \mathrm{C}-30^{\circ} \mathrm{C}$; no substrato papel, $25^{\circ} \mathrm{C}, 30^{\circ} \mathrm{C}$ e $35^{\circ} \mathrm{C}$ foram estatisticamente superiores às demais temperaturas. Em relação às temperaturas, somente $20^{\circ} \mathrm{C}$ e $20^{\circ} \mathrm{C}-30^{\circ} \mathrm{C}$ apresentaram diferenças significativas entre os substratos; em ambas temperaturas, os substratos solo e vermiculita apresentaram os mais altos valores de germinação. As médias gerais demonstraram que os substratos solo e vermiculita e as temperaturas de $25^{\circ} \mathrm{C}, 30^{\circ} \mathrm{C}$ e $35^{\circ} \mathrm{C}$ apresentaram valores estatisticamente superiores.

Em relação aos valores médios de IVG (Tabela 2), verificou-se, pela interação significativa do substrato $\mathrm{x}$ temperatura, que nas temperaturas de $20^{\circ} \mathrm{C}$ e $20^{\circ} \mathrm{C}-30^{\circ} \mathrm{C}$, os substratos vermiculita e solo foram superiores estatisticamente ao substrato papel. Nas demais temperaturas, os substratos não apresentaram diferenças significativas entre si. Nos substratos, os valores médios de IVG das temperaturas de $25^{\circ} \mathrm{C}$ e $30^{\circ} \mathrm{C}$, no substrato vermiculita, foram superiores aos obtidos a $20^{\circ} \mathrm{C}$ e $20^{\circ} \mathrm{C}-30^{\circ} \mathrm{C}$, mas semelhantes aos obtidos a $35^{\circ} \mathrm{C}$. No substrato solo, $30^{\circ} \mathrm{C}$ foi superior às temperaturas de $20^{\circ} \mathrm{C}$ e $20^{\circ} \mathrm{C}-30^{\circ} \mathrm{C}$; entretanto, essa temperatura não apresentou diferença estatística quando comparada a $25^{\circ} \mathrm{Ce} 35^{\circ} \mathrm{C}$.
Nos estudos relacionados à metodologia de germinação de espécies florestais, Oliveira et al. (1989) recomendaram o uso de temperaturas alternadas, já que essas simulariam o ambiente natural de florestas, onde as flutuações de temperaturas ocorrem, principalmente, pela abertura de clareiras, que estimula a germinação de espécies pioneiras. Em alguns casos, a alternância de temperaturas aumentou consideravelmente a germinação, como o verificado em sementes de Syzygium aromaticum (Maeda et al., 1991) e Torresia acreana (Albrecht et al., 1986). Todavia, a alternância de temperaturas pode inibir parcialmente o desenvolvimento da germinação, como encontrado por Carneiro \& Pires (1983) em sementes de Ricinus comunis e por Andrade \& Pereira (1994) em sementes de Cedrela odorata, à semelhança dos resultados obtidos com as sementes de Genipa americana.

Os maiores valores de germinação e de IVG foram encontrados na vermiculita e no solo. Comportamento semelhante foi verificado por Pereira \& Andrade (1994) em sementes de maracujá, em que a germinação apresentou valores superiores em substrato vermiculita. Walker (1975), citado por Pinto (1987), atribuiu a alta capacidade de retenção de água e as condições adequadas de aeração da vermiculita às suas propriedades físico-químicas. Tais características podem ter contribuído para o aumento do porcentual germinativo de sementes de Genipa americana nesse substrato, em comparação com os demais.

TABELA 1. Valores médios de germinação (\%) obtidos na contagem final (70 dias), de acordo com as temperaturas e substratos testados em sementes de Genipa americana ${ }^{1}$.

\begin{tabular}{lcccc}
\hline Temperatura & \multicolumn{3}{c}{ Substrato } & \multirow{2}{*}{ Média } \\
\cline { 2 - 4 } & Papel & Solo & Vermiculita & \\
\hline $20^{\circ} \mathrm{C}$ & $4,0 \mathrm{bB}$ & $69,3 \mathrm{aA}$ & $50,7 \mathrm{bA}$ & $41,3 \mathrm{~b}$ \\
$25^{\circ} \mathrm{C}$ & $90,3 \mathrm{aA}$ & $86,7 \mathrm{aA}$ & $89,3 \mathrm{aA}$ & $88,8 \mathrm{a}$ \\
$30^{\circ} \mathrm{C}$ & $86,7 \mathrm{aA}$ & $86,7 \mathrm{aA}$ & $89,3 \mathrm{aA}$ & $87,6 \mathrm{a}$ \\
$35^{\circ} \mathrm{C}$ & $89,3 \mathrm{aA}$ & $89,3 \mathrm{aA}$ & $84,0 \mathrm{aA}$ & $87,5 \mathrm{a}$ \\
$20^{\circ} \mathrm{C}-30^{\circ} \mathrm{C}$ & $12,0 \mathrm{bB}$ & $66,7 \mathrm{aA}$ & $65,3 \mathrm{abA}$ & $47,9 \mathrm{~b}$ \\
\hline Médias & $57,1 \mathrm{~B}$ & $79,7 \mathrm{~A}$ & $75,7 \mathrm{~A}$ & \\
\hline
\end{tabular}

${ }^{1}$ Letras minúsculas discriminam médias nas colunas e letras maiúsculas discriminam médias nas linhas, pelo teste de Tukey a 5\% de probabilidade. 
TABELA2. Valores médios de índice de velocidade de germinação (IVG), obtidos de acordo com as temperaturas e substratos testados em sementes de Genipa americana ${ }^{1}$.

\begin{tabular}{lllll}
\hline Temperatura & \multicolumn{3}{c}{ Substrato } & \multirow{2}{*}{ Média } \\
\cline { 2 - 4 } & Papel & Solo & Vermiculita & \\
\hline $20^{\circ} \mathrm{C}$ & $0,01 \mathrm{bC}$ & $0,24 \mathrm{bA}$ & $0,19 \mathrm{bB}$ & $0,15 \mathrm{~b}$ \\
$25^{\circ} \mathrm{C}$ & $0,48 \mathrm{aA}$ & $0,46 \mathrm{abA}$ & $0,57 \mathrm{aA}$ & $0,50 \mathrm{a}$ \\
$30^{\circ} \mathrm{C}$ & $0,40 \mathrm{aA}$ & $0,57 \mathrm{aA}$ & $0,54 \mathrm{aA}$ & $0,50 \mathrm{a}$ \\
$35^{\circ} \mathrm{C}$ & $0,41 \mathrm{aA}$ & $0,41 \mathrm{abA}$ & $0,36 \mathrm{abA}$ & $0,39 \mathrm{a}$ \\
$20^{\circ} \mathrm{C}-30^{\circ} \mathrm{C}$ & $0,03 \mathrm{bC}$ & $0,21 \mathrm{bB}$ & $0,24 \mathrm{bA}$ & $0,16 \mathrm{~b}$ \\
\hline Média & $0,27 \mathrm{~B}$ & $0,38 \mathrm{~A}$ & $0,38 \mathrm{~A}$ & \\
\hline${ }^{1}$ Letras minúsculas discriminam médias nas colunas e letras maiúsculas discriminam médias nas linhas, pelo teste de Tukey a 5\% de probabilidade.
\end{tabular}

\section{CONCLUSÕES}

1. A germinação de Genipa americana L. é do tipo faneroepígea; os cotilédones são fotossintetizantes na plântula, apesar de morfologicamente diferentes do primeiro par de folhas.

2. As temperaturas constantes de $25^{\circ} \mathrm{C}, 30^{\circ} \mathrm{C}$ e $35^{\circ} \mathrm{C}$ e os substratos vermiculita e solo são os mais adequados para a germinação das sementes dessa espécie.

\section{REFERÊNCIAS}

ALBRECHT, J.M.F.; ALBUQUERQUE, M.C.L.F.; SILVA, F.S.M. Influência da temperatura e do substrato na germinação de sementes de cerejeira. Revista Brasileira de Sementes, Brasília, v.8, p.49-55, 1986.

ANDRADE, A.C.S.; PEREIRA, T.S. Efeito do substrato e da temperatura na germinação e no vigor de sementes de cedro - Cedrela odorata L. (Meliaceae). Revista Brasileira de Sementes, Brasília, v.16, p.34-40, 1994.

BARBOSA, L.M.; BARBOSA, J.M.; BATISTA, E.A.; MANTOVANI, W.; VERONESE, S.A.; ANDREANI, R. Ensaios para estabelecimento de modelos para recuperação de áreas degradadas de matas ciliares, Mogi-Guaçú (SP). Nota Prévia. In: SIMPÓSIO SOBRE MATA CILIAR, 1., 1989, Campinas. Anais. Campinas : Fundação CARGILL, 1989. p.268-283.
BEWLEY, D.D.; BLACK, M. Seeds: physiology of development and germination. New York : Plenum, 1994. 445p.

BRASIL. Ministério da Agricultura e Reforma Agrária. Regras para análise de sementes. Brasília : LAVARV/ SNAD, 1992. 365p.

CARNEIRO, J.W.P.; MARTINS, E.N.; BERTONHA, A. Influência da temperatura e de substratos na germinação e no vigor de sementes de "Stevia" (Stevia rebaudiana (Bert.) Bertoni. Revista Brasileira de Sementes, Brasília, v.9, p.101-106, 1987.

CARNEIRO, J.W.P.; PIRES, J.C. Influência da temperatura e do substrato na germinação de sementes de mamona. Revista Brasileira de Sementes, Brasília, v.5, p.127-131, 1983.

DUKE, J.A. On tropical tree. 1. Seeds, seedling, systems and systematics. Annals of the Missouri Botanical Garden, Missouri, v.56, p.125-161, 1969.

DUKE, J.A.; POLHILL, R.M. Seedlings of Leguminosae. In: POLHILL, R.M.; RAVEN, P.H. (Eds.). Advances in legume systematics. Kew : Royal Botanical Gardens, 1981. v.2, p.941-949.

FAO (Rome, Italy). Food and fruit-bearing forest species 3: examples from Latin America. Rome, 1986. 308p. (FAO Forestry Paper, 44/3).

GARWOOD, N.C. Morphology and ecology of seedlings, fruits and seeds of selected Panamanian species. Botanische Jahrbuecher fuer Systematik, Stuttgart, v.117, p.1-152, 1995. 
LORENZI, H. Árvores brasileiras: manual de identificação de plantas arbóreas nativas do Brasil. São Paulo : Plantarum, 1992. 365p.

MAEDA, J.A.; BOVI, M.L.A.; BOVI, O.A.; LAGO, A.A Germinação de sementes de craveiro-da-índia: efeito de temperatura, polpa do fruto e tratamento fungicida. Pesquisa Agropecuária Brasileira, Brasília, v.26, n.6, p.893-899, 1991

MAGUIRE, J.D. Speed of germination aid selection and evaluation for seedling emergence and vigour. Crop Science, Madison, v.2, p.176-177, 1962.

MAYER, A.M.; POLJAKOFF-MAYBER, A. The germination of seeds. New York : The McMillan Company, 1989. 270p.

MIQUEL, S. Morphologie fonctionelle de plantules d'especes forestiéres du Gabon. Bulletin du Museum d'Histoire Naturelle de Paris, Paris, v.9, p.101-121, 1987.

OLIVEIRA, E.C. Morfologia de plântulas. In: AGUIAR, I.V.; PIÑA-RODRIGUES, F.C.M.; FIGLIOLIA, M.B. (Coords.). Sementes florestais tropicais. Brasília : ABRATES, 1993. p.175-213.

OLIVEIRA，E.C.; PIÑA-RODRIGUES，F.C.M.; FIGLIOLIA, M.B. Propostas para a padronização de metodologias em análise de sementes florestais. Revista Brasileira de Sementes, Brasília, v.11, p.1-42, 1989.

OLIVEIRA, M.T.; BELTRATI, C.M. Morfologia e desenvolvimento das plântulas de Inga fagifolia e Inga uruguensis. Turrialba, San Jose, v.42, p.306-313, 1992.

PARRA, P.G. Estudio de la morfologia externa de plantulas de Calliandra gracilis, Mimosa arenosa, Mimosa camporum y Mimosa tenuifolia. Revista de la Facultad de Agronomía, Maracay, v.13, n.1/4, p.311-350, 1984.

PEREIRA, T.S.; ANDRADE, A.C.S. Germinação de Psidium guajava L. e Passiflora edulis S. - Efeito da temperatura, do substrato e morfologia do desenvolvimento pós-seminal. Revista Brasileira de Sementes, Brasília, v.16, p.58-62, 1994.

PINTO, J.R. Perdas e movimento de P, K, Ca e Mg em um solo de tabuleiro costeiro tratado com vermiculita expandida. Recife : [ s.n.], 1987. 45p.

POPINIGIS, F. Fisiologia de sementes. Brasília : AGIPLAN, 1985. 289p.

STEARN, W.T. Botanical latin. New York : Hafner, 1983. $566 \mathrm{p}$.

STEEL, R.G.D.; TORRIE, J.H. Principles and procedures of statistics: a biometrical approach. New York : McGraw Hill, 1980. 633p.

VAZQUEZ-YANES, C.; OROZCO-SEGOVIA, A. Seed germination of a tropical rain forest pionner tree (Heliocarpus donnell smithii) in response to diurnal fluctuations of temperature. Physiologia Plantarum, Copenhagen, v.56, p.295-298, 1982.

VILLAGOMEZ, A.Y;; VILLASENOR, R.R.; SALINAS, M.J.R. Lineamento para el funcionamiento de um laboratorio de semillas. Mexico : INIA, 1979. $128 \mathrm{p}$.

VOGEL, E.F. Seedlings of dicotyledons: structure, development, types descriptions of 150 woody Malesian taxa. Wageningen : Centre for Agricultural Publishing and Documentation, 1980. 445p. 